\title{
Weight gain in patients with severe atopic dermatitis treated with dupilumab: a cohort study
}

Emma Kristin Johansson ${ }^{1,2^{*}}$ (D) Lina Ulrika Ivert ${ }^{1,3}$, Baltzar Bradley ${ }^{3}$, Maria Lundqvist ${ }^{3}$ and Maria Bradley ${ }^{1,3}$

\begin{abstract}
Background: Dupilumab, targeting the interleukin-4a receptor and inhibiting the action of interleukin-4 and interleukin-13, was recently approved for treatment of moderate to severe atopic dermatitis. There is limited data on long-term effects and safety among patients with severe atopic dermatitis treated with dupilumab. Weight gain was observed among patients treated with dupilumab in our clinic. The aim was to describe weight change in a cohort study of patients with severe atopic dermatitis treated with dupilumab from baseline to follow-up after 12 months, and to analyze if weight change was associated with effect of treatment, reported appetite, and/or disturbed night sleep due to itching.
\end{abstract}

Methods: All patients with atopic dermatitis receiving systemic treatment at the Unit of Dermatology, Karolinska University Hospital, have been registered and monitored consecutively since January 2017. This cohort constituted all patients who started treatment on dupilumab or methotrexate between 10 January 2017 and 30 June 2019 with at least 6 months of follow-up within the study period. The following variables were monitored at start of and during treatment: Eczema Severity Score Index, Patient-Oriented Eczema Measure, visual analogue scale for pruritus $10 \mathrm{~cm}$, Montgomery-Åsberg Depression Rating Scale, Dermatology Life Quality Index, and weight. Data analyses were performed using two-sample Wilcoxon-Mann-Whitney rank-sum test, or the Wilcoxon matched-pairs sign-rank test with a $p$-value $<0.05$ considered as statistically significant.

Results: Patients treated with dupilumab $(n=12)$ gained weight (mean $6.1 \mathrm{~kg}$, range [0.1-18.0], $p=0.002$ ) after 1 year on treatment. The majority of patients showed a good response to treatment with dupilumab $(n=11)$; at follow-up at 6, 9, or 12 months, they reached EASI-90 $(n=6)$, EASI-75 $(n=4)$, or EASI-50 $(n=1)$. There was no significant association between weight gain and treatment response, reported appetite, or disturbed night-sleep due to itch. Patients treated with methotrexate showed no significant weight change $(n=8)$.

Conclusions: To our knowledge, this is the first report on a possible association between weight gain and dupilumab treatment; the extent of the association is yet to be seen, as is the mechanism behind this finding.

Keywords: Adverse event, Atopic eczema, Biologics, Side effect

\footnotetext{
* Correspondence: emma.k.johansson@sll.se

'Dermatology and Venereology Unit, Department of Medicine Solna,

Karolinska Institutet, SE-171 77 Stockholm, Sweden

${ }^{2}$ Dermatological and Venereal Clinic, Södersjukhuset, SE-118 83 Stockholm,

Sweden

Full list of author information is available at the end of the article
}

(c) The Author(s). 2020 Open Access This article is licensed under a Creative Commons Attribution 4.0 International License, which permits use, sharing, adaptation, distribution and reproduction in any medium or format, as long as you give appropriate credit to the original author(s) and the source, provide a link to the Creative Commons licence, and indicate if changes were made. The images or other third party material in this article are included in the article's Creative Commons licence, unless indicated otherwise in a credit line to the material. If material is not included in the article's Creative Commons licence and your intended use is not permitted by statutory regulation or exceeds the permitted use, you will need to obtain permission directly from the copyright holder. To view a copy of this licence, visit http://creativecommons.org/licenses/by/4.0/ The Creative Commons Public Domain Dedication waiver (http://creativecommons.org/publicdomain/zero/1.0/) applies to the data made available in this article, unless otherwise stated in a credit line to the data. 


\section{Background}

Atopic dermatitis (AD) (i.e., atopic eczema) is a common inflammatory skin disease characterized by dry skin and episodes of itchy skin lesions [1]. Topical therapy with emollients and anti-inflammatory glucocorticoids and/or calcineurin inhibitors constitutes the first-line treatment [2]. Systemic immunosuppressive treatment with ciclosporin, methotrexate, azathioprine or mycophenolic acid is commonly used for refractory cases with severe $A D$ [3]. Biologics targeting the interleukin (IL) $-4 \alpha$ receptor (dupilumab) have recently been approved for moderate to severe AD [4]. There is limited data on long-term effects and safety among patients with severe AD treated with dupilumab. At our clinic at the Unit of Dermatology, Karolinska University Hospital, several patients receiving treatment with dupilumab reported weight gain.

To our knowledge, there is no previously published report that weight gain could be associated with dupilumab treatment among patients with AD. However, patients with psoriasis, rheumatoid arthritis (RA) or inflammatory bowel disease (IBD) treated with other biologics are reported to put on weight during treatment [5-8]. The mechanism behind the weight gain is not fully understood. One possible explanation could be that the disease leads to energy consumption, meaning that the patient will gain weight if treatment is successful and diet is unchanged. Patients with AD scratch due to itching during night sleep and suffer from sleep disturbance more frequently than healthy controls [9, 10]. Jenney et al. have previously described that scratching during sleep increased oxygen consumption in $\mathrm{AD}$ patients [11], and others have reported that children and adolescents with severe AD and disturbed night sleep had a reversible short stature [12]. Both these findings could be due to increased energy expenditure; weight gain during treatment with dupilumab might be a consequence of a reversal in increased energy expenditure.

Another possible explanation is that inhibition of the IL-4 $\alpha$ receptor interferes with signaling pathways in other organs or systems in the body. The IL- $4 \alpha$ receptor signaling is a crucial regulator in the development of post-natal brown fat [13]. Brown fat is associated with cold-induced non-shivering thermogenesis and maintained activation of brown fat is negatively correlated with obesity [14]. Studies on mice have shown that overexpression of IL-13 prevents high-fat diet-induced weight gain without affecting food consumption [15], and administration of IL-4 increased brown fat mass and the thermogenic capacity to decrease established obesity [16]. As IL-4 and IL-13 have an anti-inflammatory effect in the fat metabolism, and treatment with dupilumab blocks IL-4 and IL-13, this might interfere with activation of brown fat and thus increase the risk for obesity in patients with $\mathrm{AD}$.
In this cohort study, we aimed to describe weight change among patients with severe AD treated with dupilumab from baseline to follow-up after 12 months. Further, we wanted to analyze if weight change was associated with effect of treatment, reported appetite, and/ or disturbed night sleep due to itching.

\section{Methods}

We used prospectively collected data from our research register of patients with severe $\mathrm{AD}$ who had received systemic immunosuppressive treatment. All patients with $\mathrm{AD}$ on systemic treatment are consecutively registered since 10 January 2017. Data on sex, age, atopic comorbidity, filaggrin mutations, IgE sensitization, and contact allergy, among other things, are recorded at inclusion [17] and the following variables are monitored at start of and during treatment: Eczema Severity Score Index (EASI) [18], Patient-Oriented Eczema Measure (POEM) [18], visual analogue scale for pruritus $10 \mathrm{~cm}$ (VAS) [19], Montgomery-Åsberg Depression Rating Scale (MADRS) [20], Dermatology Life Quality Index (DLQI) [21], and weight. Questionnaire data used in this study, was collected as standard practice from all patients with $\mathrm{AD}$ at each visit to the dermatologist (at start of treatment, after 1 month on treatment, after 3 months and every third to sixth month thereafter). In total, 41 patients started treatment with dupilumab and/or methotrexate between 10 January 2017 and 30 June 2019. Patients with follow-up of less than 6 months $(n=$ $15)$ or missing values regarding weight $(n=8)$ were excluded. The final study population consisted patients with $\mathrm{AD}$ who had undergone treatment with dupilumab $(n=12)$ and/or methotrexate $(n=8)$. All patients who started treatment with dupilumab had previously been treated with methotrexate, but only two of them were treated with both methotrexate and dupilumab and had a follow-up of at least 6 months within the study period. These two patients are included in both the methotrexate group and the dupilumab group in the analyses.

\section{Definitions}

Successful treatment was defined as $75 \%$ improvement in EASI score (EASI-75) from baseline to follow-up at 6, 9, or 12 months and/or improvement in EASI score $\geq 6.6$ (minimal clinically important difference) from baseline to follow-up at 6, 9, or 12 months [22]. Minimal clinically important difference in symptoms was defined as a reduction $\geq 4$ in POEM score [22].

Reduced appetite was asked about in MADRS: "Do you experience a reduced appetite compared with when feeling well? Scale 0-6; 0: Normal or increased appetite; 2: Slightly reduced appetite; 4: No appetite / food is tasteless 6: Need persuasion to eat." 
Disturbed night sleep due to itching was asked about in POEM: "Over the last week have many nights has your sleep been disturbed because of the eczema? Scale 0-6; 0 No days 1: 1-2 days 2: 3-4 days 3: 5-6 days 4: Every day".

\section{Statistics}

Background characteristics and outcome measures at baseline were expressed as percentage of the total number of individuals observed, or mean value, and $95 \%$ confidence intervals $(95 \% \mathrm{CI}) . P$ values were calculated with the two-sample Wilcoxon-Mann-Whitney rank-sum test, and $p<0.05$ was considered significant. The Wilcoxon matched-pairs sign-rank test was used to compare outcome measures (weight, EASI, POEM, VAS, DLQI, MADRS) at baseline with outcome measures at follow-up among patients treated with dupilumab or methotrexate separately. All statistical calculations were performed with Stata statistical software (release 12.1; StataCorp, College Station, TX, USA).

\section{Ethics}

This study was approved by the Regional Ethical Review Board at Karolinska Institutet, Stockholm. Informed written consent was provided by all participants.

\section{Results}

In total, 12 patients (median age 50.5 years, range 2360) had started treatment with dupilumab and eight patients (median age 56 years, range 43-81) had started treatment with methotrexate. Patients treated with dupilumab had been given at least one other systemic immunosuppressive treatment before dupilumab was considered: methotrexate $(n=12)$, ciclosporin $(n=6)$, omalizumab $(n=2)$, apremilast $(n=3)$, acitretin $(n=1)$, azathioprine $(n=1)$, and/or alitretinoin $(n=1)$. Half of the patients $(n=4)$ treated with methotrexate had not used any systemic immunosuppressive treatment at baseline. The other half had been treated with omalizumab $(n=1)$, apremilast $(n=$ $1)$, acitretin $(n=1)$, and/or alitretinoin $(n=2)$. During the study period, none of the study participants used systemic glucocorticoids.

All patients were classified as having moderate or severe $A D$ refractory to conventional treatment. Outcome measures for AD at baseline are shown in Table 1. Age, sex, EASI, POEM, VAS for pruritus, DLQI, and weight were comparable between patients with dupilumab and patients with methotrexate at baseline (start of treatment). DLQI was significantly higher among patients with methotrexate $(p=0.025)$, and EASI was significantly higher among patients with dupilumab ( $p=$ 0.045) (Table 1).

At follow-up, patients treated with dupilumab had gained weight significantly (mean weight change: $6.1 \mathrm{~kg}$,
Table 1 Characteristics of patients with severe atopic dermatitis at start of treatment

\begin{tabular}{|c|c|c|c|c|c|}
\hline & \multicolumn{2}{|c|}{ Methotrexate $(n=8)$} & \multicolumn{2}{|c|}{ Dupilumab $(n=12)$} & \multirow{2}{*}{$\begin{array}{l}p \\
\text { value }\end{array}$} \\
\hline & Mean & $95 \% \mathrm{Cl}$ & Mean & $95 \% \mathrm{Cl}$ & \\
\hline Age (years) & 56.4 & $46.0-66.7$ & 46.9 & $39.6-54.2$ & 0.189 \\
\hline Male sex (\%) & 62.5 & $24.5-91.5$ & 83.3 & $51.6-97.9$ & 0.304 \\
\hline EASI & 15.3 & $8.9-21.7$ & 27.6 & $18.7-36.5$ & $0.045^{*}$ \\
\hline POEM & 18.0 & $11.2-24.8$ & 18.6 & $13.5-23.7$ & 0.816 \\
\hline VAS & 6.0 & $3.5-8.4$ & 5.9 & $4.0-7.8$ & 0.817 \\
\hline DLQI & 17 & $12.3-21.7$ & 9.4 & $4.5-14.3$ & $0.025^{*}$ \\
\hline MADRS & 11.7 & $6.3-17.1$ & 12.8 & $3.8-21.9$ & 0.421 \\
\hline Weight (kg) & 75.3 & $64.7-85.8$ & 84.8 & $73.4-96.1$ & 0.142 \\
\hline BMI $\left(\mathrm{kg} / \mathrm{m}^{2}\right)$ & 24.7 & 19.9-36.1 & 27.3 & $24.0-28.4$ & 0.123 \\
\hline
\end{tabular}

Abbreviations: $\mathrm{Cl}$ Confidence interval, EASI Eczema area severity score, POEM Patient-oriented eczema measure, VAS Visual analogue scale, DLQI

Dermatology life quality index, MADRS Montgomery-Åsberg depression rating scale, BMI Body Mass Index

Significant differences marked with *. $P$ values calculated using two-sample Wilcoxon-Mann-Whitney rank-sum tests

range [0.1-18.0], $p=0.002)$, while the weight of patients with methotrexate had not changed (mean weight change: $-3.1 \mathrm{~kg}$, range [-17.0-2.0], $p=0.161)$, Fig. 1 . The majority of the patients showed a positive response to treatment (Fig. 2). Most patients treated with dupilumab had improved all outcome measures (EASI, POEM, VAS, DLQI, and MADRS) significantly. Moreover, at follow-up at 6, 9, or 12 months, they reached EASI-90 $(n=6)$, EASI-75 $(n=4)$, or EASI-50 $(n=1)$, and had a minimal clinically important difference in POEM $(n=10,1$ missing value). One patient did not respond to treatment with dupilumab. Patients treated with methotrexate reached EASI-90 $(n=3)$, EASI$75(n=2)$, or EASI-50 $(n=1)$ and had a minimal clinically important difference in POEM $(n=6)$. Two patients did not respond to treatment with methotrexate. Treatment was stopped and they switched to dupilumab instead.

\section{Weight change in relation to treatment response}

We performed a sensitivity analysis among patients with AD successfully treated with dupilumab $(n=11)$ and methotrexate $(n=6)$, Table 2 . Patients successfully treated with dupilumab were comparable with all patients treated with dupilumab (mean weight change: 6.6 $\mathrm{kg}$, range [0.1-18.0]). Patients treated with methotrexate had a significant response to treatment (EASI, VAS, DLQI, and MADRS were significantly reduced) and tended to lose weight from baseline to follow-up (mean weight change: $-4.3 \mathrm{~kg}$, range [-17.0-2.0]), but not significantly. 


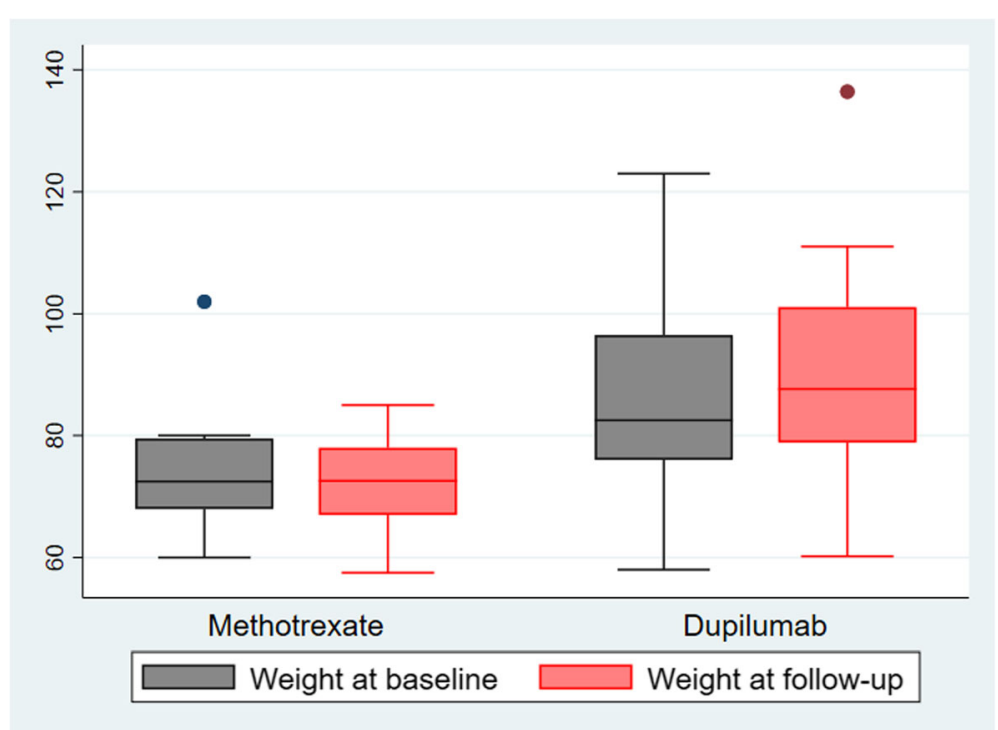

Fig. 1 Median weight at baseline and follow-up 12 months later among patients with systemic treatment. The analysis is stratified by methotrexate $(n=8)$ and dupilumab ( $n=12)$. Follow-up at 12 months $(n=15)$, at 9 months $(n=2)$, at 6 months $(n=3)$ due to missing value at 12 months or short time of follow-up. The difference in weight between baseline and follow-up was significant among patients treated with dupilumab ( $p=0.002)$ but not among patients treated with methotrexate $(p=0.161)$. $P$ values calculated using Wilcoxon matched-pairs sign-rank tests

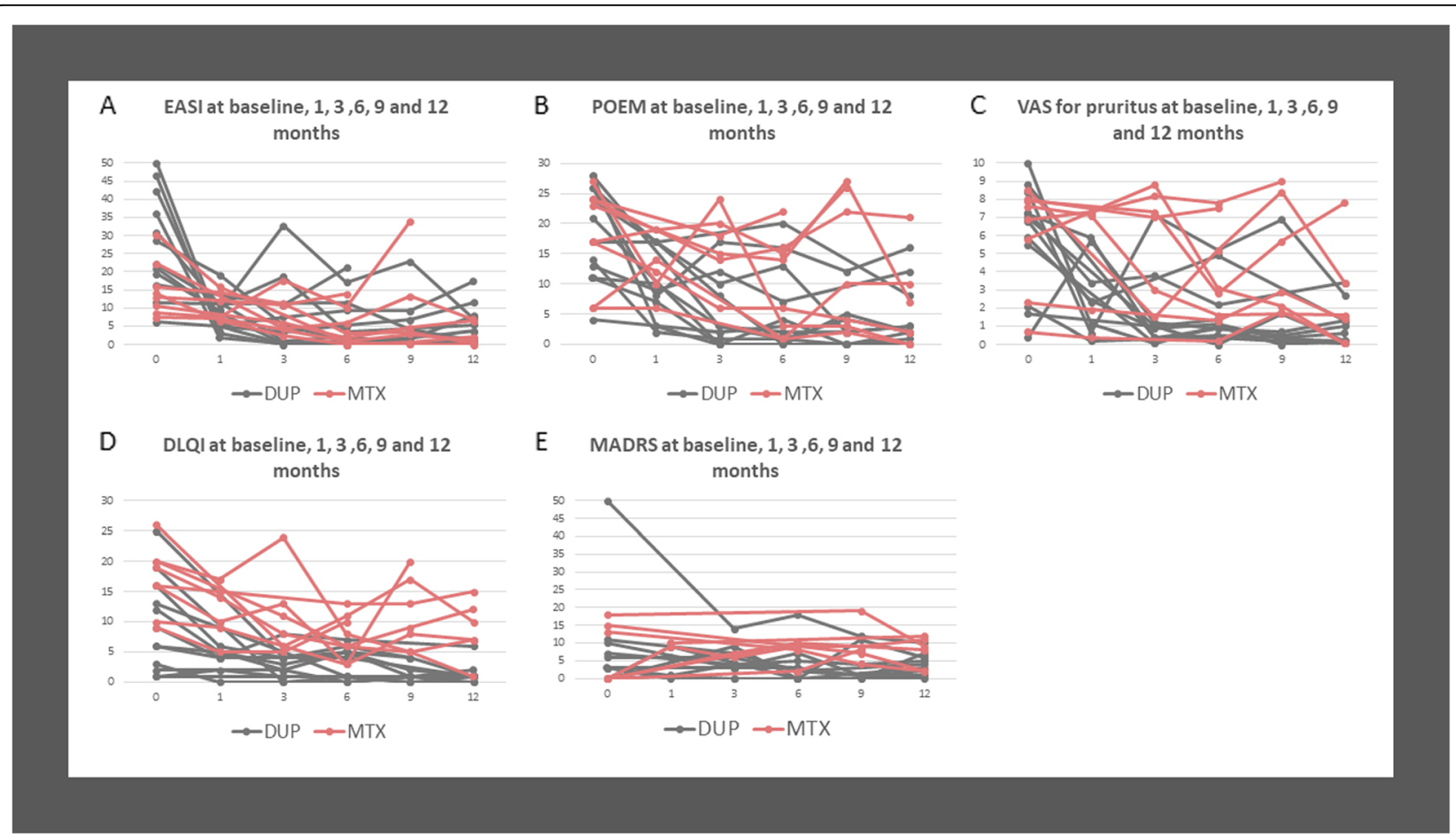

Fig. 2 Outcome measures monitored during treatment with dupilumab or methotrexate in adults with atopic dermatitis. a Eczema Area Severity Index (EASI), b Patient-Oriented Eczema Measure (POEM), c Pruritus Visual Analogue Scale Score (VAS, 0-10 cm), d Dermatology Life Quality Index (DLQI), e Montgomery-Åsberg Depression Rating Scale (MADRS). Dupilumab (DUP) in gray $(n=12)$ and methotrexate (MTX) in red $(n=8)$ 
Table 2 Outcome measurements among patients with atopic dermatitis successfully treated with methotrexate or dupilumab

\begin{tabular}{|c|c|c|c|c|c|c|}
\hline & Methotrexate & & & Dupilumab ( $n$ & & \\
\hline & At start & At follow-up ${ }^{a}$ & & At start & At follow-up ${ }^{a}$ & \\
\hline & Mean (range) & Mean (range) & & Mean (range) & Mean (range) & value \\
\hline$\overline{E^{\prime} A S I^{b}}$ & $16.8(7.4-30.3)$ & $2.8(0-6.8)$ & $0.028^{*}$ & $28.6(6.2-50)$ & $5.2(0.3-17.5)$ & $0.003^{*}$ \\
\hline POEM ${ }^{c}$ & $17.2(6-27)$ & $6.7(0-21)$ & 0.075 & $19.9(11-28)$ & $4.9(0-16)$ & $0.005^{*}$ \\
\hline $\operatorname{VAS}^{\mathrm{C}}$ & $5.7(0.7-8.5)$ & $2.4(0.1-7.8)$ & $0.028^{*}$ & $6.3(0.4-10)$ & $1.1(0.1-3.4)$ & $0.007^{*}$ \\
\hline$\left.D L Q\right|^{b}$ & $18.5(10-26)$ & $8.7(1-15)$ & $0.028^{*}$ & $10.2(1-25)$ & $1.6(0-6)$ & $0.005^{*}$ \\
\hline MADRS $^{c}$ & $14.6(13-18)$ & $7.3(3-12)$ & $0.034^{*}$ & $13.7(1-50)$ & $3.9(0-10)$ & $0.028^{*}$ \\
\hline Weight $^{\mathrm{d}}(\mathrm{kg})$ & $74.8(60-102)$ & $70.5(57.7-85)$ & 0.075 & $87.1(58-123)$ & $93.6(65.5-136.4)$ & $0.003^{*}$ \\
\hline
\end{tabular}

Abbreviations: EASI Eczema area severity score, POEM Patient-oriented eczema measure, VAS Visual analogue scale, DLQI Dermatology life quality index, MADRS Montgomery-Åsberg depression rating scale

Significant differences marked with *. $P$ values calculated using Wilcoxon matched-pairs sign-rank tests

${ }^{a}$ Follow-up after 12 months of treatment. Some patients had shorter follow-up and some variables were missing at 12 months, but collected at 6 or 9 months of follow-up

${ }^{\mathrm{b}}$ Follow-up at 12 months $(n=16)$, at 9 months $(n=1)$

${ }^{c}$ Follow-up at 12 months $(n=16)$, missing value at follow-up $(n=1)$

${ }^{d}$ Follow-up at 12 months $(n=15)$, at 9 months $(n=1)$, at 6 months $(n=1)$

\section{Appetite and sleep disturbance due to itching in relation to weight change}

At baseline, the majority of patients treated successfully with dupilumab and methotrexate reported normal or increased appetite (7 of 11 and 3 of 5 [1 missing data], respectively). The other patients reported slightly reduced appetite ( 1 or 2 on scale $0-6)$. No patient reported no appetite or need persuasion to eat ( $\geq 3$ on scale 0-6) (Additional files 1 and 2). In the dupilumab group, 3 of 4 patients still reported slightly reduced appetite at follow-up, and one patient reported normal or increased appetite. Among patients treated with methotrexate, 2 of 2 patients were improved and reported normal or increased appetite at follow-up. In the visual assessment, there was no correlation between reported appetite and weight change among patients treated with dupilumab or methotrexate.

Disturbed night sleep Every day last week (4, scale 04) was reported at baseline among 6 of 10 (1 missing data) patients treated successfully with dupilumab. At follow-up, one patient still reported disturbed night sleep Every day last week, and all others $(n=9)$ reported disturbed night sleep No days (0, scale $0-4)$. In all, 5 of 10 clearly improved their night sleep from baseline to follow-up. For five patients, night sleep was unchanged (one patient reported disturbed night sleep Every day, and the other four reported No days). Both patients with improved night sleep $(n=5)$ and those with unchanged night sleep $(n=5)$ gained weight (mean weight change: $7.2 \mathrm{~kg}$ and $3.8 \mathrm{~kg}$, respectively) with no significant difference between the groups $(p=0.076)$. Among patients treated successfully with methotrexate, all reported disturbed night sleep in the last week at baseline (1-2 days $[n=1], 3-4$ days $[n=1], 5-6$ days $[n=2)$, Every day $[n=$ $2])$. All improved their night sleep from baseline to followup; two patients who reported Every day at baseline reported 1-2 days and 3-4 days, respectively, at follow-up. All others reported No days at follow-up. Patients treated successfully with methotrexate and who improved their night sleep during treatment did not gain weight (mean weight change: $-4.3 \mathrm{~kg}$ ) (Additional files 1 and 2).

\section{Discussion}

Patients with severe $\mathrm{AD}$ treated with dupilumab gained weight, a mean of $6.1 \mathrm{~kg}$, over the course of 1 year on treatment. To the best of our knowledge, this is the first report on an association between treatment with dupilumab and weight gain. In this cohort study, with a limited number of participants, there was no obvious relation between weight gain and appetite, disturbed night sleep due to itching, or treatment response.

Our finding is in line with previous reports on weight gain during treatment with other biologics, such as antitumor necrosis factor (TNF)- $\alpha$ and IL-6 inhibitors. Patients with psoriasis increased their lean (fat-free) mass and fat mass during treatment with anti-TNF- $\alpha$ [6] and patients with RA treated with tocilizumab (an IL-6 inhibitor) for 1 year gained weight significantly, without change in fat mass. The RA patients gained mainly muscle mass and the authors suggested that inhibition of IL-6 could be effective in reversing muscle loss in RA patients [7]. In patients with IBD, weight gain as well as reverse growth failure in children are expected due to improvement of the symptoms during treatment. However, excessive weight gain has been reported in children with IBD exposed to anti-TNF- $\alpha$ [5]. In our study, the patients with $\mathrm{AD}$ treated with dupilumab seemed to put on more weight (mean weight gain: $6.1 \mathrm{~kg}$ ) compared with RA patients treated with an IL-6 inhibitor (mean weight gain: $1.9 \mathrm{~kg}$ ) [7], RA patients treated with antiTNF- $\alpha$ (mean weight gain: $1.8 \mathrm{~kg}$ ) [8], or patients with psoriasis treated with adalimumab (anti-TNF- $\alpha$; mean 
weight gain: $2.2 \mathrm{~kg}$ ) [23]. To our knowledge, there are no previous reports regarding an association between use of the anti-IL- $4 \alpha$ receptor as a treatment target and weight change.

It is possible that disturbed night sleep due to itching and continuous inflammation increase energy consumption, meaning that the energy need is reduced upon improvement. Thus, if patients on successful treatment do not change their diet, they will gain weight. Patients with AD scratch their skin during night sleep more often than healthy controls (24 min vs. 2 min, respectively) [10] and one small study (nine patients with $\mathrm{AD}$ ) showed an increased oxygen consumption due to scratching during night sleep [11]. However, Hon et al. compared $13 \mathrm{AD}$ patients with eight healthy controls and did not find an increased resting energy consumption, increased oxygen consumption, or increased carbon dioxide production during sleep among $\mathrm{AD}$ patients. They speculated that altered energy expenditure during night sleep is unlikely among children with AD [24]. In our study, patients with severe $\mathrm{AD}$ successfully treated with dupilumab gained weight, but patients successfully treated with methotrexate did not. The weight gain among patients with dupilumab was not significant associated with improvement in night sleep. Therefore, it is unlikely that reduction in energy expenditure explains the findings in our study. The larger weight gain as compared with that among RA patients and psoriasis patients treated with other biologics supports the idea that weight gain could be a direct side effect of dupilumab. Inhibition of the activation in brown fat is a possible mechanism behind the weight gain [13]. However, this area needs further exploration.

The strengths of this study were that data on weight and outcome measures were registered consecutively for all patients with $\mathrm{AD}$ treated with systemic drugs in a clinical setting, and that we could use patients who received other treatments for comparison. The outcome measures for $\mathrm{AD}$ used in this study are all validated [18, 19, 25, 26], and EASI and POEM are recommended by the group Harmonizing Outcome Measures for Eczema [18], which is also a strength. The small number of participants is a limitation, especially the few patients successfully treated with methotrexate used for comparison. Another limitation is that patients with dupilumab treatment differed from patients with methotrexate regarding EASI and DLQI at baseline, and tended to differ in weight, although not significantly. However, the treatment response was significant and comparable among patients who responded to treatment. Nausea is a common adverse event among patients using methotrexate [27]. Among patients treated with methotrexate, it is therefore possible that effects or side effects of the treatment biased the relation between weight gain and appetite or energy consumption. Thus, we cannot rule out that the difference in weight gain between the groups might be explained by methotrexate rather than by dupilumab. However, this is less likely since the patients, regardless of treatment, reported similar appetite levels. Furthermore, it is our experience that patients suffering from severe nausea will switch drugs before 1 year of treatment has passed.

\section{Conclusion}

We report weight gain as an unexpected and unexplained side effect of dupilumab treatment, from a clinical setting among patients with severe AD. Therefore, we recommend monitoring of weight during treatment with dupilumab and informing patients of this possible side effect. To our knowledge, this is the first report on a possible association between weight gain and treatment with dupilumab and the extent of the association is yet to be seen, as is the mechanism behind this finding. Thus, larger studies are warranted to confirm this finding.

\section{Supplementary information}

Supplementary information accompanies this paper at https://doi.org/10. 1186/s12895-020-00103-0.

Additional file 1. Change in weight, appetite, and sleep disturbance from baseline to follow-up 12 months later among patients with atopic dermatitis successfully treated with dupilumab $(n=11)$.

Additional file 2. Change in weight, appetite, and sleep disturbance from baseline to follow-up 12 months later among patients with atopic dermatitis successfully treated with methotrexate $(n=6)$.

\section{Abbreviations}

AD: Atopic dermatitis; BMI: Body Mass Index; Cl: Confidence interval; DLQI: Dermatology life quality index; EASI: Eczema area severity score; IBD: Inflammatory bowel disease; IL: Interleukin; MADRS: Montgomery-Åsberg depression rating scale; POEM: Patient-oriented eczema measure; RA: Rheumatoid arthritis; TNF: Tumor necrosis factor; VAS: Visual analogue scale

\section{Acknowledgements}

We would like to thank senior professor Carl-Fredrik Wahlgren who together with $M B$ and LUI initiated and designed our research register for patients with severe $A D$ who had received systemic immunosuppressive treatment, and all our patients who take their time to participate in the register.

\section{Authors' contributions}

EKJ and $M B$ designed the study. $M B, L U I$, and $M L$ coordinated and performed the data collection. EKJ and BB analyzed the data and provided the figures. All authors had full access to all the data and participated in the interpretation of the findings. EKJ wrote the initial draft. All authors revised the manuscript critically and provided important intellectual input and gave the final approval of the version published. MB is the main guarantor.

\section{Funding}

The study was funded by grants from the Stockholm County Council (ALF project) in the analysis, interpretation of data, and writing the manuscript.

Availability of data and materials

The datasets used and/or analyzed during the current study are available from the corresponding author on reasonable request. 


\section{Ethics approval and consent to participate}

This study was approved by the Regional Ethical Review Board at Karolinska Institutet, Stockholm (2010/345-31/2). Informed written consent was provided by all participants.

\section{Consent for publication}

Not applicable.

\section{Competing interests}

EKJ has received speaker honoraria and/or been part of the advisory board for Sanofi-Genzyme, Leo Pharma, ACO, Novartis, and Galenica. LUI has received speaker honoraria from ACO and Sanofi-Genzyme. MB has received research funding from Sanofi-Genzyme, speaker honoraria from Novartis, AstraZeneca, AbbVie, Leo Pharma, Celgene, and been part of the advisory board for Sanofi-Genzyme, Novartis, Lilly, AbbVie, and Leo Pharma.

\section{Author details}

'Dermatology and Venereology Unit, Department of Medicine Solna, Karolinska Institutet, SE-171 77 Stockholm, Sweden. ${ }^{2}$ Dermatological and Venereal Clinic, Södersjukhuset, SE-118 83 Stockholm, Sweden. ${ }^{3}$ Department of Dermatology, Karolinska University Hospital Solna, SE-171 76 Stockholm, Sweden.

Received: 17 March 2020 Accepted: 16 September 2020

Published online: 22 September 2020

\section{References}

1. Weidinger S, Beck LA, Bieber T, Kabashima K, Irvine AD. Atopic dermatitis. Nat Rev Dis Primers. 2018:4(1):1.

2. Wollenberg A, Barbarot S, Bieber T, Christen-Zaech S, Deleuran M, FinkWagner A, et al. Consensus-based European guidelines for treatment of atopic eczema (atopic dermatitis) in adults and children: part I. J Eur Acad Dermatol Venereol. 2018;32(5):657-82.

3. Wollenberg A, Barbarot S, Bieber T, Christen-Zaech S, Deleuran M, FinkWagner A, et al. Consensus-based European guidelines for treatment of atopic eczema (atopic dermatitis) in adults and children: part II. J Eur Acad Dermatol Venereol. 2018;32(6):850-78.

4. Wang FP, Tang XJ, Wei CQ, Xu LR, Mao H, Luo FM. Dupilumab treatment in moderate-to-severe atopic dermatitis: a systematic review and metaanalysis. J Dermatol Sci. 2018;90(2):190-8.

5. Haas L, Chevalier R, Major BT, Enders F, Kumar S, Tung J. Biologic agents are associated with excessive weight gain in children with inflammatory bowel disease. Dig Dis Sci. 2017;62(11):3110-6.

6. Renzo LD, Saraceno R, Schipani C, Rizzo M, Bianchi A, Noce A, et al. Prospective assessment of body weight and body composition changes in patients with psoriasis receiving anti-TNF-alpha treatment. Dermatol Ther. 2011;24(4):446-51.

7. Tournadre A, Pereira B, Dutheil F, Giraud C, Courteix D, Sapin V, et al Changes in body composition and metabolic profile during interleukin 6 inhibition in rheumatoid arthritis. J Cachexia Sarcopenia Muscle. 2017;8(4): 639-46.

8. Brown RA, Spina D, Butt S, Summers GD. Long-term effects of anti-tumour necrosis factor therapy on weight in patients with rheumatoid arthritis. Clin Rheumatol. 2012:31(3):455-61.

9. Endo K, Sumitsuji H, Fukuzumi T, Adachi J, Aoki T. Evaluation of scratch movements by a new scratch-monitor to analyze nocturnal itching in atopic dermatitis. Acta Derm Venereol. 1997;77(6):432-5.

10. Noro Y, Omoto Y, Umeda K, Tanaka F, Shiratsuka Y, Yamada T, et al. Novel acoustic evaluation system for scratching behavior in itching dermatitis: rapid and accurate analysis for nocturnal scratching of atopic dermatitis patients. J Dermatol. 2014;41(3):233-8.

11. Jenney ME, Childs C, Mabin D, Beswick MV, David TJ. Oxygen consumption during sleep in atopic dermatitis. Arch Dis Child. 1995;72(2):144-6.

12. Silverberg $\mathrm{J}$, Paller AS. Association between eczema and stature in 9 US population-based studies. JAMA Dermatol. 2015;151(4):401-9.

13. Lee MW, Odegaard Jl, Mukundan L, Qiu Y, Molofsky AB, Nussbaum JC, et al. Activated type 2 innate lymphoid cells regulate beige fat biogenesis. Cell. 2015;160(1-2):74-87.

14. Nedergaard J, Bengtsson T, Cannon B. Three years with adult human brown adipose tissue. Ann N Y Acad Sci. 2010;1212:E20-36.
15. Darkhal P, Gao M, Ma Y, Liu D. Blocking high-fat diet-induced obesity, insulin resistance and fatty liver by overexpression of II-13 gene in mice. Int J Obes. 2015;39(8):1292-9.

16. Qiu Y, Nguyen KD, Odegaard Jl, Cui X, Tian X, Locksley RM, et al. Eosinophils and type 2 cytokine signaling in macrophages orchestrate development of functional beige fat. Cell. 2014;157(6):1292-308.

17. Ivert LU, Wahlgren CF, Ivert L, Lundqvist M, Bradley M. Eye complications during dupilumab treatment for severe atopic dermatitis. Acta Derm Venereol. 2019;99(4):375-8.

18. Grinich EE, Schmitt J, Kuster D, Spuls PI, Williams HC, Chalmers JR, et al. Standardized reporting of the eczema area and severity index (EASI) and the patient-oriented eczema measure (POEM): a recommendation by the Harmonising outcome measures for eczema (HOME) initiative. $\mathrm{Br} J$ Dermatol. 2018;179(2):540-1.

19. Phan NQ, Blome C, Fritz F, Gerss J, Reich A, Ebata T, et al. Assessment of pruritus intensity: prospective study on validity and reliability of the visual analogue scale, numerical rating scale and verbal rating scale in 471 patients with chronic pruritus. Acta Derm Venereol. 2012;92(5):502-7.

20. Montgomery SA, Asberg M. A new depression scale designed to be sensitive to change. Br J Psychiatry. 1979;134:382-9.

21. Finlay AY, Khan GK. Dermatology life quality index (DLQI)--a simple practical measure for routine clinical use. Clin Exp Dermatol. 1994;19(3):210-6.

22. Schram ME, Spuls PI, Leeflang MM, Lindeboom R, Bos JD, Schmitt J. EASI, (objective) SCORAD and POEM for atopic eczema: responsiveness and minimal clinically important difference. Allergy. 2012;67(1):99-106.

23. Saraceno R, Schipani C, Mazzotta A, Esposito M, Di Renzo L, De Lorenzo A et al. Effect of anti-tumor necrosis factor-alpha therapies on body mass index in patients with psoriasis. Pharmacol Res. 2008;57(4):290-5.

24. Hon KL, Leung TF, Ma KC, Li AM, Wong Y, Yin JA, et al. Resting energy expenditure, oxygen consumption and carbon dioxide production during sleep in children with atopic dermatitis. J Dermatol Treatment. 2005;16(1): 22-5.

25. Mottram P, Wilson K, Copeland J. Validation of the Hamilton depression rating scale and Montgommery and Asberg rating scales in terms of AGEC AT depression cases. Int J Geriatr Psychiatry. 2000;15(12):1113-9.

26. Holm EA, Wulf HC, Stegmann H, Jemec GB. Life quality assessment among patients with atopic eczema. Br J Dermatol. 2006;154(4):719-25.

27. Warren RB, Weatherhead SC, Smith CH, Exton LS, Mohd Mustapa MF, Kirby $B$, et al. British Association of Dermatologists' guidelines for the safe and effective prescribing of methotrexate for skin disease 2016. Br J Dermatol. 2016;175(1):23-44.

\section{Publisher's Note}

Springer Nature remains neutral with regard to jurisdictional claims in published maps and institutional affiliations.

Ready to submit your research? Choose BMC and benefit from:

- fast, convenient online submission

- thorough peer review by experienced researchers in your field

- rapid publication on acceptance

- support for research data, including large and complex data types

- gold Open Access which fosters wider collaboration and increased citations

- maximum visibility for your research: over $100 \mathrm{M}$ website views per year

At BMC, research is always in progress.

Learn more biomedcentral.com/submissions 